\title{
Introducción. \\ Márgenes de la academia: cuando los lingüistas conversan sobre lingüística
}

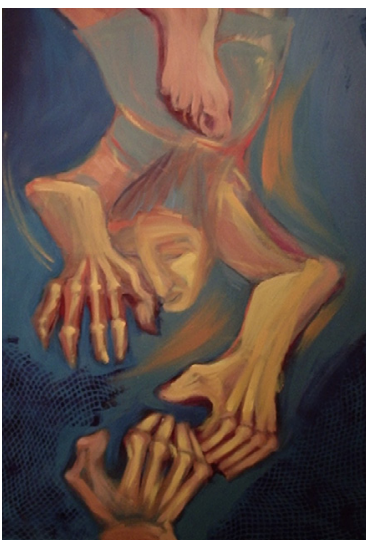

Salvio Martín Menéndez

Instituto de Lingüística, Universidad de Buenos Aires, Argentina

Dentro del complejo entramado de los géneros discursivos, la entrevista se ubica en un lugar privilegiado. Las razones de este privilegio son varias, pero destacaremos dos. La primera es que su organización básica y simple permite atravesarlos de un modo similar, con diferentes niveles de elaboración, de cómo los hablantes usamos habitualmente el lenguaje: la interacción conversacional cara a cara. La segunda, este género permite elaborar con mayor simplicidad y direccionalidad cuestiones (desde el dato autobiográfico al error productivo) que otras modalidades no permiten.

Si bien en el ámbito académico, no suele ser, tal vez, la modalidad más frecuente hay ejemplos notables que muestran su representatividad. Basta citar ejemplos tradicionales como las conversaciones de Herman Parret con Chomsky, Chafe, Greimas, Halliday, Lamb, Martinet, Hartamnn, Lakoff entre otros, en Discussing Language editado en 1974 y Dialogues avec Noam Chomsky de Mitsou Ronat de 1977 hasta Interviews with M. A. K. Halliday. Language Turned Back on Himself editado por J. R. Martin en 2013.

El presente dossier se inscribe en esta tradición y pretende dar un panorama de las diferentes maneras de enfocar el fenómeno lingüístico. Nos permite, además, inaugurar una modalidad que, no necesariamente en forma de un dossier, incorporaremos.

Reunimos aquí cuatro entrevistas llevadas a cabo en diferentes momentos y lugares a un conjunto de lingüistas cuya importancia radica en el hecho de ser referentes insoslayables en sus especialidades.

William Labov y Gilliam Sankoff son entevistados por Andrea Menegotto. En ella, se logra reconstruir un paralelo entre una historia académica muy conocida - la de la sociolingüística cuantitativa - con una historia de vida, mucho menos conocida, centrada en intereses perdurables; esto permite dar a esa historia académica otra dimensión. El contrapunto entre ambos es constante. Sirve como ejemplo altamente representativo, lo que dispara la pregunta de cómo se le ocurrió a Labov el modo de recolección de datos.

Robert Hodge y Gunther Kress son entrevistados por Ignacio Pérez González y Werner Pertot. Abordan centralmente el problema de definir la relación entre lenguaje e ideología para ver cómo esto aparece representado en los 
medios. Rescatan, valoran e interpretan el alcance del relativismo whorfiano sin llegar a ningún extremo y destacando siempre la importancia del posicionamiento que se adopta para enfocar las cosas. La relación entre el punto de vista y la construcción que este supone les permite mostrar no sólo las características sino los efectos de la ideología que no es una abstracción idealizada sino una posición particular en un momento específico.

Chirstian Plantin es entrevistado por Alejandra Vitale. Su modelo argumentativo conforma la columna sobre la que se organiza el diálogo. Y a partir de allí logra tomar posición y analizar su propuesta al explicar que la argumentación para él es una actividad interaccional más que dialéctica en la que hay siempre tres personas involucradas; la tercera es el marco en el que la actividad interaccional se inscriba. Agrega, además, que la base de una buena argumentación radica en una documentación exhaustiva y advierte que más allá de que el ejercicio argumentativo fortalece las democracias, no debe olvidarse que en las dictaduras también se argumenta.

Concepción Company Company es entrevistada por José Luis Ramírez Luengo. Referente indiscutida de la filología y de la historia de la lengua traza una historia de su vida académica que le sirve para mostrar los cambios que ha sufrido el enfoque de la subdisciplina en la que ocupa un lugar mayor. Valora a sus maestros y despliega, con un virtuosismo lejos de la solemnidad habitual en algunos círculos académicos, cómo su propia práctica como investigadora se ha venido desarrollando. Advierte con sagacidad no exenta de polémica: "Tras 40 años de trabajo en gramática histórica, tengo la firme convicción de que la última palabra de los cambios no está en la lengua, está en la historia, en la cultura, en la literatura, en las modas sociolingüísticas y comunicativas"

Los cuatro reportajes tienen más puntos en común que lo que, en una primera mirada purista, podrían llegar a tener. Comparten una premisa fundamental que aún hoy debe mencionarse: el lenguaje es un proceso instrumental condicionado por factores cognitivos, sociales, culturales e históricos. Pensarlo más allá de la subjetividad de los hablantes (y en consecuencia, acontextualmente) es crear una ilusión de lo que debería y no de lo efectivamente es: materialidad discursiva sometida a diferentes puntos de vista analíticos.

Una cita final de Concepción Company-Company lo expresa con poderosa claridad:

El porqué último -tú, que eres filólogo nato, seguro que piensas igual- no está en el sistema, está en la cabeza de los hablantes, en las estructuras sociales, en si la lengua en cuestión está al amparo de estructuras gubernamentales que la acogen y que fomentan una cultura escrita y oral en ella, o por el contrario está desamparada del poder, alejada de los marcos sociales y culturales hegemónicos... eso me causa gran, gran curiosidad. 


\section{Q Bibliografía}

» Martin, James R. (ed). (2013) Interviews with M. A. K. Halliday. Language Turned Back on Himself. Bloomsbury, London and New York.

"Parret, Herman (1974). Discussing Language. Dialogues with Wallace L. Chafe, Noam Chomsky, Algirdas J. Greimas, M. A. K. Halliday, Peter Hartmann, George Lakoff, Sydney M. Lamb, André Martinet, James McCawley, Sebastian K. Saumjan, Jacques Bouveresse. Le Hague, Mouton

》 Ronat, Mitsou (1977), Dialogue avec Noam Chomsky, Flammarion, Paris 